\title{
Music, Sports, and the Sound of Writing
}

\author{
Deborah Justice* \\ $06 / 20 / 2018^{\dagger}$
}

\begin{abstract}
Coming from a disciplinary background in ethnomusicology, I wanted to create an assignment outside of the norm in writing studies; rather than having the students understand sound as a text to be read, I wanted them to be able to read and respond to sound with sound. The majority of students in my "Music and Sports" course were journalism or music industry students who were fulfilling an elective requirement on the way to careers in sports broadcasting or news reporting. I wanted the students to experiment and enact our departmental goals of writing ethnographically about music and culture through well-constructed and well-referenced narratives that also would result in an interactive "real world" application beyond standard response papers or blogs. To this end, students had to respond to fairly open-ended prompts by recording three minutes of audio that included three citations to class readings and three audio clips of their choosing. The students grew dramatically in their ability to choose and contextualize the sound clips as effectively as article quotes in advancing their analyses. With technological developments like recording apps and free editing software, students can use sound itself as a primary source to propel their arguments. This assignment demonstrates how instead of describing sounds, we can now weave them into spoken narratives and then allow readers to hear them to support our arguments. We can now write with music.
\end{abstract}

When I was teaching at Syracuse University, one particularly predominant feature of the student population stood out to me: these people love sports. From wild support for the nearly pro-level basketball games at the Carrier Dome to the lacrosse tournaments that relate to the neighboring indigenous Onondaga Nation, SU students bleed orange. They also love sounds about sports - fan chants, warm-up songs, the marching band... the list goes on. Tasked with developing courses that would tap my areas of interest and expertise while also drawing students to the Department of Art and Music Histories, I

\footnotetext{
${ }^{*}$ Cornell University; Setnor School of Music, Syracuse University, deborah.ruth.justice@gmail.com. Copyright 2018 Deborah Justice. This work is licensed under a Creative Commons AttributionNonCommercial 4.0 International License (http://creativecommons.org/licenses/by-nc/4.0/).

${ }^{\dagger}$ Submitted, 04/07/2017; Accepted, 02/07/2018.
} 
guessed that a course entitled "Music and Sports" would have a wait list every semester. I was right.

The popular appeal of sport and sound brought classes with a non-major demographic similar to my department's popular History of Rock survey course. The majority of these students were taking "Music and Sports" to fulfil an elective requirement. While that type of enrollment is excellent for broadening our departmental presence on campus as a whole and supports the ideals of holistic liberal arts education, it also means that these students were most likely not taking our courses sequentially. With only a music student or two, I had classrooms full of business school students, human ecology and sports management majors, and budding sports journalists. Many of these students who were planning careers in sports broadcasting or news reporting were already gifted authors in journalistic styles of writing. Many of them were also familiar with using sound clips of sports in their radio reporting. These foci and skill sets are similar to (and sometimes overlap with) the typical methodologies and ethnographic writing styles typically used in my home discipline of ethnomusicology. For ethnomusicologists, ethnographic research means analyzing a topic through how subjects subjectively speak for themselves, with a holistic focus on music-making - by researchers, the subjects, both alike, and even possibly third parties. Rather than a journalist pursuing a story with particular questions to answer that dictate the flow of the conversation with a subject, ethnomusicologists doing ethnography study music as subjective communicative systems that more fully reveal themselves to outsiders and insiders alike over the course of investigation and most often do not fully translate into text alone.

Given these considerations, I wanted to create an assignment that would promote intellectual curiosity by going beyond standard written response papers. While I wanted students to have the comforting anchor of writing in ways already familiar to them, I also wanted a way to encourage them to branch out into the complexities of ethnography. I wanted to do something outside of the norm in writing studies; rather than having the students understand sound as a text to be read, I wanted them to be able to read and respond to sound with sound. I wanted to create an assignment that married research, audio examples, and also allowed the possibility of students writing with a subjective and editorial slant. I wanted to give them the possibility of moving their voices anywhere on the spectrum from the "objectivity" of a field researcher to a well-informed editorial columnist. I also wanted the students to be pushed a bit to experiment and enact our departmental goals of writing ethnographically about music and culture through well-constructed and well-referenced narratives that also would result in an interactive "real world" application beyond standard response papers or blogs.

I designed an assignment that gave students a relatively open-ended prompt; for example, "Why do we play the national anthem at sporting events?" Or "How do links between music and sport impact marketing?" Students had to record three minutes of audio in answer to this question that involved three citations to class readings and three audio clips of their choosing. Students peer-reviewed their assignments in small groups in class on the due date, while I assigned a final grade upon later review. 
Student reception to the assignment was positive. Initially, they were very excited about this assignment when they read the syllabus because it looked like "Music and Sports" required hardly any writing. Aside from these audio assignments (35\% of the grade) which never had to be turned in in any type of written form, the class was only assessed on Attendance/Participation (10\%), Daily Reading Quizzes (15\%), Midterm Exam (20\%), and Final Exam (20\%). While it was true that relatively little written work was required to be turned in, I have always appreciated the observation from ethnographers Emerson, Fretz, and Shaw (1995) that "All writing, even seemingly straightforward descriptive writing, is a construction" (p. 66). Construction requires work, and this holds true for planned out audio narratives as well as the written word. In effect, I worked to create this audio assignment as a set of tasks that would "trick" students into doing the constructive mental work of writing - by creating well-constructed and well-referenced narratives-but that also would result in an interactive "real world" application beyond standard response papers or blogs.

Going beyond standard response papers was a key goal of this assignment. Traditional response papers or other written assignments tend to divorce the subject of musical inquiry from the stuff of it; in other words, we write silently about sounds. This disconnect between words on a page and sound has formed a central intellectual concern in ethnomusicology. Following a history of discussion between ethnomusicology and linguistics, ethnomusicologists understand "speaking" and "musicking" as two distinct and not completely commensurable modes of communication. Ethnomusicologists generally see not only words describing sound, but also musical scores' prescriptive or descriptive representations of sound, as both necessarily reductive and dangerously editorial.

Integrating sound with words, or juxtaposing musical sounds to create arguments without words, has therefore been an area of significant investment from the work of founderof-the-field Charles Seeger on into contemporary ethnomusicological engagements with sound studies. Our field tries to move beyond just writing about music, to do more than explain a score theoretically or talk about a composer's motivations. Various tactics have tried to bring the sounds to the reader: pictures of the musical score may be included in a text and referenced along the lines of "In the final measure, the singer ornaments the melody, as transcribed in example 3"; books may come with a listening $\mathrm{CD}$; publishing houses may host audio examples online, or authors may post sound clips on their own websites so that readers can interact with the source material under discussion. These are useful tactics, and yet most ethnomusicological assignments for undergraduate non-majors are traditional papers "in the speech mode" (not musicking). With technological developments like recording apps and free editing software, however, students can use sound itself as a primary source to propel their arguments. Instead of describing sounds, we can now weave them into spoken narratives and then allow readers to hear them to support our arguments. We can now write with music.

Another learning goal for the project was to promote intellectual curiosity in the students. Traditional response papers - having each student write a response paper in isolation, each student responding to the same prompt, and then having me grade the papers 
without students responding to each other's work - did not strike me as a very useful or real-world-applicable exercise. Ethnomusicologists do not expect their colleagues to write on exactly the same aspects of music as each other, nor do professionals in any field perform work redundant to that of their colleagues. Rather, we work collaboratively and build off of each other's ideas to solve problems. My students have been interesting individuals who bring unique perspectives and life experiences to their work, so I wanted to give them to opportunity to respond to very open-ended prompts, interact with each other's ideas, and see where they would run with that ball. To that end, I did not want students to have to craft tight arguments, but rather to let their responses run the gamut from a thesis-driven argument to a subjective opinion to a non-rambling train of thought. I told them to think of a variety of short NPR pieces from This American Life, Story Core, SoundBeat, and similar productions as examples. Everyone's assignments were not to fit into a cookie-cutter template. The range of responses across assignments proved this to be a highly successful tactic, as the method of feedback and peer-evaluation (discussed below) showed students how many different scholarly perspectives could result from the same prompts.

Feedback came in two parts, from me as the professor and from fellow students. The audio assignments were due by class time, so I was not pre-screening submissions. As soon as students came into class on a due date, I broke them into their assigned feedback groups, which remained constant throughout the semester so that they could see the evolution in each other's work. This provided good motivation for students to get their work done in a timely fashion because they would have to admit their lack of preparedness to the group if they had not completed the assignment. Since late assignments earned a zero for negatively impacting the group, this policy did not result in fewer students in class when assignments were due.

The groups would each select a member's assignment to listen to first, and then the earbuds came out. Students listened intently to their peers' work, taking notes to provide constructive criticism and honest feedback to each member. The main gist of the feedback was to be bullet-pointed and turned in to me at the end of the class.

The first few assignments were a learning curve for some of the students. Straightforward non-writing-related subtleties - like issues uploading to Soundcloud, not recording in a crowded dining hall, or keeping audio clips at comparable levels - caused a few bumps in the road, but overall the students were quite adept at audio editing and posting, as well as using references to support their arguments. The open-ended nature of the prompts also pushed them to create arguments rather than summaries, which was initially challenging for some of them.

A major learning goal for this assignment was for students to increase their ability to strongly integrate supporting materials and sources into their work. In my experience, many undergraduate writers often struggle to effectively integrate the required number of citations into essays and responses. Contextualization and communicating how cited material supports the author's own thoughts can be challenging and, initially, many 
"Music and Sports" students struggled with incorporating the audio. They thought that simply inserting the audio clip into their narrative flow would make the sounds obviously understandable. For example, on the first assignment about the Star-Spangled Banner, many students missed the importance of contextualizing their audio clips and submitted something like, "Francis Scott Key wrote the Star-Spangled-Banner about the War of 1812. The Americans won the war. Later, after we won World War I, Americans started singing it at ball games. $<15$ seconds of an unidentified instrumental version of the National Anthem> Today, many athletes do not want to have the anthem played before every game..." The unclear antecedent of "it" in the second sentence notwithstanding, these lines and the sound clip do not work together as strongly as they should. Why this particular clip? Who is performing it? Is it a historical clip? How does the narrative skip from 1812 to the present with such little connection?

During the peer-review, I travelled from group to group to see how the students were reviewing this type of work. Initially, student comments were often too uncritically positive; "Nice audio editing, Ian" or "Great job, Madison! I like the version of the 'Star-Spangled Banner' you chose!" In order to steer the conversation, I would gently insert myself and say something like, "Well, that is a great version, but why is it here? What exactly do you want to use it to show?" Sometimes, the student would have had a great rationale, but that explanation had not made it out of their drafting process into their final narrative. Students picked up on the goals of using the sound to make stronger points and began to ask more perceptive questions about their colleagues' choices. They were often surprised by how individual each listener's perception was and by much they then had to write about and contextualize the sounds to provide guideposts to help the listeners pick out the particular elements and aspects under discussion. Integrating sound this way helped students think about music as a bibliographic resource, as well as requiring them to master some basic ethnographic skills to understand how their colleagues were perceiving sounds.

As the semester progressed, students came to see the collective review as a chance to impress their peers with the quality of their work. They grew less self-conscious about seeing others listen to their work (many were quite shy about hearing the own recorded voices initially). They also took cues from my questions and began to press each other and ask for more clarity about why certain clips were chosen, or about why one student had used a clip to push point A, whereas another had coincidentally used the same sounds to push point B. Students got into deep discussions about the content of the assignments, since all of them were bringing such an array of examples. This fulfilled some of the major learning goals for the assignment, including students becoming more intellectually curious about angles surrounding a topic and using sound to support their reasoning.

After this in-class peer-review session, I would assess the students' work. I would grade it aurally, letting their audio play alongside my own recorder and then pausing their track when I wanted to leave a comment. At the end of their audio, I would give some overall comments and break down their final grade for them. This form of feedback mirrored the production process students had gone through, and they reported appreciating feedback 
in this form.

The aural nature of this set of assignments allowed students to think about writing as an interactive engagement, rather than dry words on a page. As an added bonus, the students also often learned from each other about editing techniques that they saw each other using to good effect. Ultimately, for everyone involved, the assignment was more time- and energy-intensive than a set of response papers, but students overwhelmingly rated this assignment positively because it cultivated a supportive learning environment and useable skills. "Writing" with the spoken word and with sound brought the class together and pushed students to think about sound and sport in new ways.

\section{Assignment}

See the Supplementary Files for this article at thepromptjournal.com for a PDF facsimile of the original formatting of this assignment.

Since so much of music and sports happens aurally, instead of writing papers, you will be producing brief audio stories in response to class readings and discussion. Think about short NPR pieces as good examples.

Your goal: 3 minutes of articulate audio that

- incorporates 3 references to class readings or speakers. Do not use outside sources. You will reference the in-class sources by saying something like: For an in - class speaker: "As Dr. Jonathan Dueck of George Washington University mentioned in his lecture, basketball blah blah blah" For a printed source: "Can your playlist choices make you faster? According to Dr. Costas Karageorghis in his chapter in Sporting Sounds, music can have a positive impact on performance."

- incorporates 3 audio clips of no more than 10 secs each. Because we will be using such brief clips, it's all under "fair educational use" so you can pull sources from wherever you like. Grab an excerpt of an MP3 from your own collection. Your own live recording from a sporting event. A sound clip captured off of YouTube/the web. My only requirement is that the sound is clear and that you use it wisely. This is substance, not filler.

While you don't need a "thesis" per se, you need to have a coherent train of thought and build an argument. This should not meander as a lost train of thought. It should address the question very directly.

Grading Rubric: Time (roughly 3 mins): 10\%; 3 References: 15\%; 3 Sound clips: 15\%; Content (directly addresses question, makes sense, contributes an insight that engages with scholarship to say something impactful): $60 \%$.

These are due posted to \#SyracuseUniversityMusic\&Sports on SoundCloud by class time. If you are late, you get a ZERO because the point of class that day then is to listen to each other's work and discuss. You will all have answered the questions differently, so we 
will talk about the approaches that you all took and why. We will peer-review what was effective and what might need some more training.

- Assignment 1: Why do we play the national anthem at sporting events?

- Assignment 2: How do links between music and sport impact marketing?

- Assignment 3: How does regional music build identity through sport?

- Assignment 4: Archival Tracks: These will be explained separately

- Assignment 5: How has the use of music in baseball stadiums evolved over time?

Note: I gave them an additional instruction sheet (reproduced below the horizontal line) that had some elaboration on how I wanted them to approach the purposefully open-ended prompts.

Outlines of example answers to the prompt "Why do we sing national anthems at sporting events?"

This could be sweet and innocent. Like, in all seriousness, "How did it come to pass that my kid sister's softball team puts their hands over their hearts and sings this song before turning cartwheels in the outfield?" Trace the history, give some examples. Done.

Or it could get political legs. More of, "Why on earth are we singing this militaristic stuff before everything?" or "How does my $5 \mathrm{k}$ to raise $\$$ for breast cancer research need political overtones?" or "With so many international professional athletes (often from countries the US of A is currently bombing) does it even make sense before NFL or NBA games?"

See? Same question. Two 100\% valid takes as long as you support with references and sound clips. You can have an opinion. It just needs to be an intelligently defended one.

\section{References}

Emerson, R. M., Fretz, R. I., \& Shaw, L. L. (1995). Writing ethnographic fieldnotes (1st ed.). University of Chicago Press. 